\title{
Synthetic nanoemulsion resembling a protein-free model of 7-ketocholesterol containing low density lipoprotein: In vitro and in vivo studies
}

\author{
Giovani M Favero ${ }^{1,2}$, Raul C Maranhão ${ }^{3}$ Durvanei A Maria ${ }^{4}$, Débora Levy ${ }^{1}$ and Sérgio P Bydlowski*1 \\ 1 Laboratory of Genetics and Molecular Hematology (LIM31), Faculdade de Medicina da Universidade de São Paulo, Brazil \\ 2 Department of General Biology, Universidade Estadual de Ponta Grossa, Paraná, Brazil \\ ${ }^{3}$ Laboratory of Lipid Metabolism, Instituto do Coração (InCor), Hospital das Clínicas da Faculdade de Medicina da Universidade de São Paulo, Brazil \\ ${ }^{4}$ Laboratório de Bioquímica e Biofísica, Instituto Butantan, São Paulo, Brazil
}

\begin{abstract}
7-ketocholesterol (7-KC) differs from cholesterol by a functional ketone group at C7. It is an oxygenated cholesterol derivative (oxysterol), commonly present in oxidized low-density lipoprotein (LDL). Oxysterols are generated and participate in several physiologic and pathophysiologic processes. For instance, the cytotoxic effects of oxidized LDL have been widely attributed to bioactive compounds like oxysterols. The toxicity is in part due to 7-KC. Here we aimed to demonstrate the possibility of incorporating 7-KC into the synthetic nanoemulsion LDE, which resembles LDL in composition and behavior. This would provide a suitable artificial particle resembling LDL to study 7-KC metabolism. We were able to incorporate 7-KC in several amounts into LDE. The incorporation was evaluated and confirmed by several methods, including gel filtration chromatography, using radiolabeled lipids. The incorporation did not change the main lipid composition characteristics of the new nanoparticle. Particle sizes were also evaluated and did not differ from LDE. In vivo studies were performed by injecting the nanoemulsion into mice. The plasma kinetics and the targeted organs were the same as described for LDE. Therefore, 7-KC-LDE maintains composition, size and some functional characteristics of LDE and could be used in experiments dealing with 7-ketocholesterol metabolism in lipoproteins.
\end{abstract}

Key terms: emulsion, LDL, LDE, 7-ketocholesterol, oxidized LDL, oxysterol.

\section{INTRODUCTION}

The low-density lipoprotein (LDL) is the main cholesterol carrier in human circulation, containing around two thirds of plasma total cholesterol (Brown and Goldstein, 2009). LDL particles are composed of molecules of triglycerides, cholesterol esters, phospholipids, and free cholesterol, and a molecule of apolipoprotein B (Hevonoja et al., 2000). It is well known that plasma levels of LDL are greatly influenced by several factors, including nutrition and genetics (Bydlowski, 1986; Bydlowski et al., 1981; 1985; 1987; 1996). They are also involved in the development of several diseases, atherosclerosis being one of them.

Oxysterols are cholesterol oxides that can be formed either by cholesterol autoxidation or by action of specific enzymes (Russel, 2000). Several oxysterols (among the more than 60 different compounds described) also occur in food, including cholesterol $\alpha$ and $\beta$-epoxides, $7 \beta$ - hydroxycholesterol and 7ketocholesterol (Osada et al., 2000). They represent a large class of regulatory molecules of biological importance, involved in sterol and lipid metabolism (Schroepfer, 2000). Oxysterols, like lipid peroxides, are generated and participate in several physiologic and pathophysiologic processes (Gregorio-King et al., 2002; Amaral et al., 2005; Javitt, 2008). Oxysterols are present in oxidized LDL and are markers for in vitro LDL oxidation (Schroepfer, 2000). The oxysterols from dietary origin can be absorbed and incorporated into lipoproteins (Osada et al., 2000). Oxidized LDL can induce an apoptotic mode of cell death in a variety of cells. The cytotoxic effects of oxidized LDL have been widely attributed to its bioactive compounds as oxysterols (Prunet et al., 2005). In fact, oxysterols have been identified as the main molecules responsible for the apoptotic activity of oxidized LDL. Their toxicity is at least in part due to 7-ketocholesterol (7-KC), oxidized at $\mathrm{C} 7$, which differs from cholesterol by a functional ketone group at C7 (Vejux et al., 2005). Increased cellular content of $7-\mathrm{KC}$ can disturb numerous metabolic pathways; competition between 7-KC and cholesterol can modify some lipid structures and alter some membrane functions (Prunet et al., 2005; Vejux et al., 2005).

Artificial emulsions resembling lipoproteins have been used for several purposes, including by us (Owens et al., 2001; Almeida et al., 2003). Recently, we have developed a synthetic chylomicron-like particle containing 7ketocolesterol (Favero et al., 2008). An artificial nanoemulsion resembling the lipid structure of LDL, which was named LDE, was described, and has the ability to bind to LDL receptors (Maranhão et al., 1993). LDE is basically composed of a cholesteryl ester core surrounded by a phospholipid monolayer. It has been shown that it can be used for metabolic studies, as well as a carrier of drugs such as antineoplastic agents or oligonucleotides (Bydlowski et al., 1995; Hungria et al., 2004; Mendes et al., 2009).

The aim of the present work was to demonstrate the possibility of incorporating $7-\mathrm{KC}$ into the synthetic nanoemulsion LDE. This would provide a suitable artificial particle resembling LDL to study $7-\mathrm{KC}$ metabolism in lipoproteins. 


\section{MATERIALS AND METHODS}

\section{Materials}

Egg phosphatidylcholine, triolein, cholesteryl oleate, cholesterol and 7-ketocholesterol were purchased from Sigma (St.Louis, MO). Lipids were $98 \%$ pure as determined by thin layer chromatography. $\left[{ }^{14} \mathrm{C}\right]$-cholesterol (sp.act.49 $\mathrm{Ci} / \mathrm{mmol}),\left[{ }^{3} \mathrm{H}\right]$-cholesteryl-oleyl-ether (sp.act.52 Ci/mmol) and $\left[{ }^{14} \mathrm{C}\right]$-phosphatidylcholine (sp.act.60 Ci/mmol) were all acquired from Amersham (Little Chalfont, UK); $\left[1,2,6{ }^{3} \mathrm{H}\right]-7-$ ketocholesterol (5-cholesten-3 $\beta$-ol-7-one, sp.act.50 Ci/mmol) was acquired from American Radiolabeled Chemicals (St Louis, MO), 99\% pure.

Preparation of $L D E$

The nanoemulsion was prepared by emulsification of a lipid mixture composed of $40 \mathrm{mg}$ cholesteryl oleate, 20mg egg phosphatidylcoline, $1 \mathrm{mg}$ triolein and $0.5 \mathrm{mg}$ cholesterol. Labeled lipids were added to the lipid mixture when necessary $\left(9 \times 10^{6} \mathrm{cpm}\right.$ each). Emulsification of lipids by prolonged ultrasonic irradiation in aqueous media and the procedure of two-step ultracentrifugation of the crude emulsion with density adjustment by addition of $\mathrm{KBr}$ and dialysis against saline solution to obtain LDE nanoemulsion were carried out by the method described previously by Ginsburg et al. $(1982 ; 1984)$ and modified by Maranhão et al. $(1986 ; 1993)$.

\section{Incorporation of 7-KC into $L D E(7-K C / L D E)$}

Fifty $\mu \mathrm{L}$ of a solution containing $0.8 \mathrm{mg} 7-\mathrm{KC}$ was added to $600 \mu \mathrm{L}$ of preformed LDE labeled with [ $\left.{ }^{3} \mathrm{H}\right]$-cholesteryl-oleylether. After incubation in a shaker bath at $37^{\circ} \mathrm{C}$ for 3 hours, $150 \mu \mathrm{L}$ Tris- $\mathrm{HCl} 0,01 \mathrm{M}, \mathrm{pH} 8.05$ was added and density was adjusted to $1.21 \mathrm{~g} / \mathrm{mL}$ with $\mathrm{KBr}$. Three $\mathrm{mL}$ of each $\mathrm{NaCl}$ solution, with different densities $(1,065 ; 1,020$; and 1,006 g/ $\mathrm{mL}$, respectively), were added, followed by ultracentrifugation at $40.000 \mathrm{xg}$ for $24 \mathrm{~h}$, at $4^{\circ} \mathrm{C}$ (Redgrave and Maranhão, 1985). Five fractions were visualized after the centrifugation, and were named fractions 1 (top) to 5 (bottom). The radioactivity in each fraction was counted in a liquid scintillation counter (LKB, Sweden).

Each fraction obtained from ultracentrifugation was also submitted separately to thin layer chromatography (TLC). After lipid extraction with chloroform/methanol, 2:1 (v/v) and evaporation of the organic phase under $\mathrm{N}_{2}$, samples were reconstituted with $800 \mu \mathrm{L}$ chloroform/methanol (Bydlowski et al., 1987). Free and esterified cholesterol, phospholipids, and 7-KC were separated by TLC $(20 \mu \mathrm{m}$ silica gel $G$ plates), using a solvent system consisting of hexane/ethyl acetate $(2: 3, \mathrm{v} / \mathrm{v})$. Before separation, pure standards for cholesterol oleate, phosphatydilcholine, free cholesterol and 7-ketocholesterol, were spotted along the side of the samples to allow visualization after exposure to iodine (Redgrave and Maranhão, 1985).

Preparation of 7-KC-LDE

Another 7-KC-containing nanoemulsion was prepared by adding 7-KC directly to the lipid mixture in the first step of the emulsification process, followed by ultrasonic irradiation, ultracentrifugation and dialysis. $\left[{ }^{14} \mathrm{C}\right]$-cholesterol and $\left[1,2,6{ }^{3} \mathrm{H}\right]-7-$-ketocholesterol added to the emulsion allowed for determination of the amount of incorporated 7KC. Different concentrations of $7-\mathrm{KC}$, in the range of 0.8 to $10 \mathrm{mg}$, were used. The final mixture was applied to gel column chromatography. Briefly, $1.5 \mathrm{~mL}$ of 7-KC-LDE was applied to an XK $16 / 25$ column of Sephadex G-200, equilibrated with Tris buffer, $\mathrm{pH} 8.0$, at a flow rate of $60 \mathrm{~mL} /$ $\mathrm{h}$ and eluted under the same conditions. Fractions of $1 \mathrm{~mL}$ were collected and counted for $\left[{ }^{3} \mathrm{H}\right]$ and $\left[{ }^{14} \mathrm{C}\right]$.

Effect of different amounts of incorporated 7-KC on particle size and composition

The changes in LDE composition promoted by different amounts of $7-\mathrm{KC}(2.0,2.5,5.0$ or $10.0 \mathrm{mg})$ capable of being incorporated were evaluated in particles obtained by both methods (7-KC/LDE and 7-KC-LDE). Double-labeled $\left[{ }^{3} \mathrm{H}\right]-$ cholesteryl-oleyl-ether $/\left[{ }^{14} \mathrm{C}\right]$-phosphatidylcholine-LDE was used. The size of particles was measured by laser light scattering (Owens et al., 2001) using a Zeta Potential Analyzer (Brookhaven Instruments Corporation, Holtscille, NY). All samples were maintained at $4^{\circ} \mathrm{C}$ and were diluted in $\mathrm{NaCl} 0.9 \%$ and filtered in a $0.22 \mathrm{~mm}$ filter immediately before diameter measurement.

\section{Plasma kinetics and biodistribution of double-labelled 7-KC-LDE}

7-KC-LDE nanoemulsions made from $5.0 \mathrm{mg}$ 7-KC were used in the in vivo studies. Plasma kinetics and biodistribution of 7-KC-LDE was determined accordingly to Rodrigues et al. (2005). Briefly, $0.3 \mathrm{mg}$ of 7-KC-LDE labelled with $\left[{ }^{3} \mathrm{H}\right]-7-\mathrm{KC}$ and $\left[{ }^{14} \mathrm{C}\right]$-free cholesterol was injected as a single bolus (150 $\mu \mathrm{L}$ ) into the retro-orbital venous plexus of C57BL/6J mice, weighing $20 \mathrm{~g}$ (60-day old). Plasma was obtained from blood samples collected after 5, 15, 30, 60 and 240 minutes from the auxiliary plexus. For biodistribution experiments, the animals were killed by cervical dislocation at the end of each experimental period. Blood was washed out and samples from several organs were obtained. Samples were weighed and tissue lipids were extracted with chloroform/methanol $(2: 1, \mathrm{v} / \mathrm{v})$ as described. Radioactivity in extracts and in plasma was measured by liquid scintillation counting.

Hematological data and liver enzymes

To evaluate toxicity of 7-KC-LDE, the nanoemulsion was intraperitoneally administered every other day to C57BL/6J mice, weighing $20 \mathrm{~g}$, in a $2.0 \mathrm{~mL}$ volume. Controls were injected with LDE. After 10 days, blood was drawn and determined for aspartate aminotransferase (AST), alanine aminotransferase (ALT), $\gamma$-glutamyltransferase (GGT), hematocrit, hemoglobin, erythrocyte count, leukocyte differential count, and eosinophil count.

\section{RESULTS}

Radioactivity from $\left[{ }^{3} \mathrm{H}\right]$-cholesteryl-oleyl-ether-LDE after density gradient ultracentrifugation was highly concentrated in fractions 3 and 4 . Very few counts were registered in fraction 1 (top), 2 or 5 (bottom). The addition of $0.8 \mathrm{mg} \mathrm{7-KC}$ 
to $\mathrm{LDE}$ (7-KC/LDE) did not change the distribution of radioactivity: $7.6 \%$ of radioactivity was present in fraction 1 ; $0.9 \%$ in fraction $2 ; 51.0 \%$ in fraction $3 ; 38.4 \%$ in fraction $4 ;$ and $2.1 \%$ in fraction 5 . Therefore, LDE density did not change by adding $0.8 \mathrm{mg}$ of $7-\mathrm{KC}$, being situated mainly in fractions 3 and 4 . The incorporation of 7-KC to LDE was confirmed by TLC (Figure 1). Again, it can be seen that 7-KC was present basically in fractions 3 and 4 .

The distribution of $\left[{ }^{3} \mathrm{H}\right]$-cholesteryl-oleyl-ether and $\left[{ }^{14} \mathrm{C}\right]-$ phosphatidylcholine in the 5 fractions obtained by ultracentrifugation was also examined, according to the amount of 7-KC incubated with LDE. It is known that cholesteryl esters (or ether) are localized at the surface of the nanoemulsion, whereas phospholipids are in the inner part. 7-KC, again, was present in fractions 3 and 4 (data not shown). Increasing the amount of 7-KC incubated with LDE to $2.0 \mathrm{mg}$ led to an increase in $\left[{ }^{3} \mathrm{H}\right]$-cholesteryl-oleyl-ether levels in fraction 1 , which did not change significantly with the increasing $7-\mathrm{KC}$ concentration up to $10.0 \mathrm{mg}$ (Table 1); in fraction 4 , the radioactivity was also present in an expressive amount, although less than in fraction 1. Regarding the distribution of $\left[{ }^{14} \mathrm{C}\right]$-phosphatidylcholine, different results were seen (Table 2). The radioactivity was found mainly in fraction 4, 1 and 3; the increase in the amount of $7-\mathrm{KC}$ incubated with LDE clearly increased the radioactivity level of fraction 4 .

A second method of production of a 7-KC-containing nanoemulsion was used. To evaluate the presence of $7-\mathrm{KC}$ in the nanoemulsion (7-KC-LDE), an exclusion chromatography was carried out. A representative curve of the radioactivity

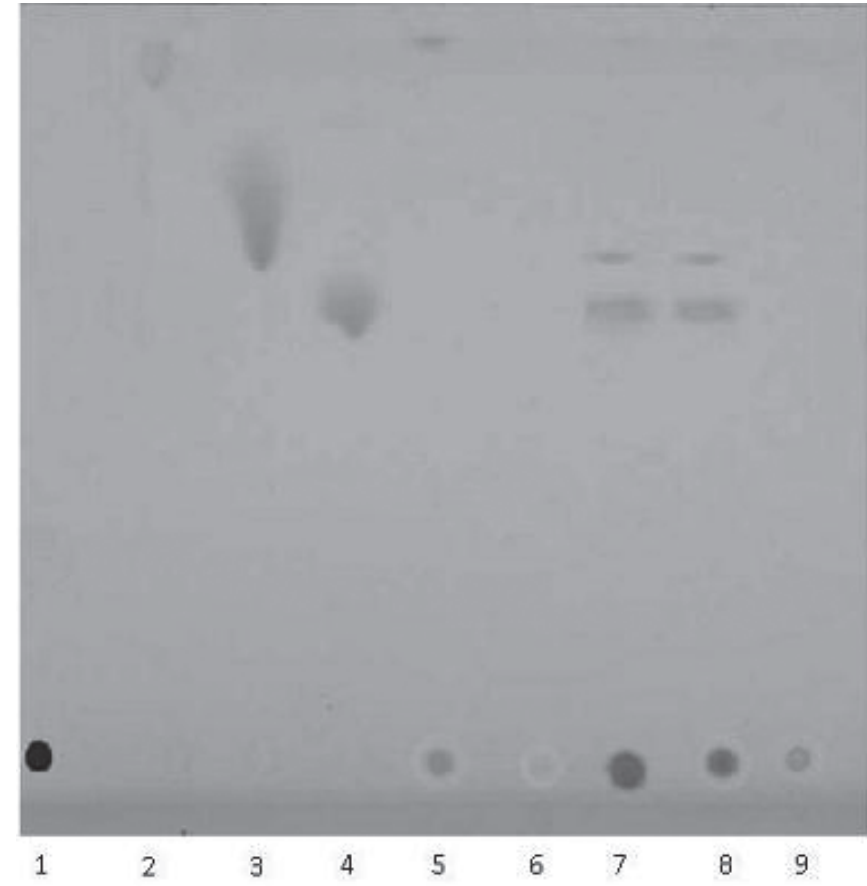

Figure 1: Thin layer chromatography of fractions obtained by ultracentrifugation after incubation of 7-ketocholesterol with LDE. 1. Phosphatydilcholine pure standard $(\mathrm{Rf}=0) ; 2$. Cholesterol oleate pure standard $(\mathrm{Rf}=0.827)$; 3 . Free cholesterol pure standard $(\mathrm{Rf}=0.65)$; 4. 7-ketocholesterol pure standard $(\mathrm{Rf}=0.56) ; 5-9$. gradient ultracentrifugation fractions $(1,2,3,4$ and 5 , respectively).

Table 1

Effect of different concentrations of 7-KC incubated with LDE (7-KC/LDE) on [ $\left.{ }^{3} \mathrm{H}\right]$-cholesteryl-oleyl-ether-LDE distribution in layers after ultracentrifugation.

\begin{tabular}{lccccc}
\hline $7-\mathrm{KC}$ & Fraction1 & Fraction 2 & Fraction 3 & Fraction 4 & Fraction 5 \\
\hline $2.0 \mathrm{mg}$ & $41780(69.3 \%)$ & $2032(3.3 \%)$ & $6394(10.6 \%)$ & $9682(16.0 \%)$ & $386(0.6 \%)$ \\
$2.5 \mathrm{mg}$ & $6345(37.3 \%)$ & $337(2.0 \%)$ & $2416(14.2 \%)$ & $7466(43.9 \%)$ & $446(2.6 \%)$ \\
$5.0 \mathrm{mg}$ & $35110(78.7 \%)$ & $233(0.5 \%)$ & $1412(3.2 \%)$ & $7553(17.0 \%)$ & $301(0.6 \%)$ \\
$10.0 \mathrm{mg}$ & $39561(53.3 \%)$ & $1808(2.4 \%)$ & $4072(5.5 \%)$ & $27966(37.7 \%)$ & $771(1.0 \%)$ \\
\hline
\end{tabular}

Results are expressed as cpm and \% of total radioactivity

\section{Table 2}

Effect of different concentrations of 7-KC incubated with LDE (7-KC/LDE) on $\left[{ }^{14} \mathrm{C}\right]$-phosphatidylcholine-LDE distribution in layers after ultracentrifugation.

\begin{tabular}{lccccc}
\hline $7-$ KC & Fraction 1 & Fraction 2 & Fraction 3 & Fraction 4 & Fraction 5 \\
\hline $2.0 \mathrm{mg}$ & $8412(25.2 \%)$ & $1847(5.5 \%)$ & $9163(27.4 \%)$ & $13393(40.1 \%)$ & $578(1.7 \%)$ \\
$2.5 \mathrm{mg}$ & $10950(38.7 \%)$ & $198(0.7 \%)$ & $3835(13.5 \%)$ & $12591(44.6 \%)$ & $681(2.4 \%)$ \\
$5.0 \mathrm{mg}$ & $3336(17.5 \%)$ & $131(0.7 \%)$ & $2531(13.3 \%)$ & $12565(66.1 \%)$ & $446(2.3 \%)$ \\
$10.0 \mathrm{mg}$ & $6363(9.9 \%)$ & $550(0.9 \%)$ & $4555(7.1 \%)$ & $51811(80.4 \%)$ & $1129(1.7 \%)$ \\
\hline
\end{tabular}


in 7-KC-LDE eluted from column is shown in Figure 2. The elution of both radio-labelled compounds, $\left[{ }^{14} \mathrm{C}\right]$-cholesterol and $\left[1,2,6-{ }^{3} \mathrm{H}\right]-7-$ ketocholesterol, were similar, suggesting a total association of 7-ketocholestol to the nanoemulsion.

The size of the particle in each experimental situation was determined (Table 3). It can be seen that nanoparticles, mainly in fraction 3 and also in fraction 4 , where $7-\mathrm{KC}$ is present, was a similar size as LDE, at a 7-KC concentration of 2.0 and $2.5 \mathrm{mg}$. With higher 7-KC concentrations, the particle size was also much higher.

On the other hand, the diameter of 7-KC-LDE isolated by gel column chromatography was the same size as LDE alone, independent of the amount of 7-KC added, at least up to 10 mg (Table 4).

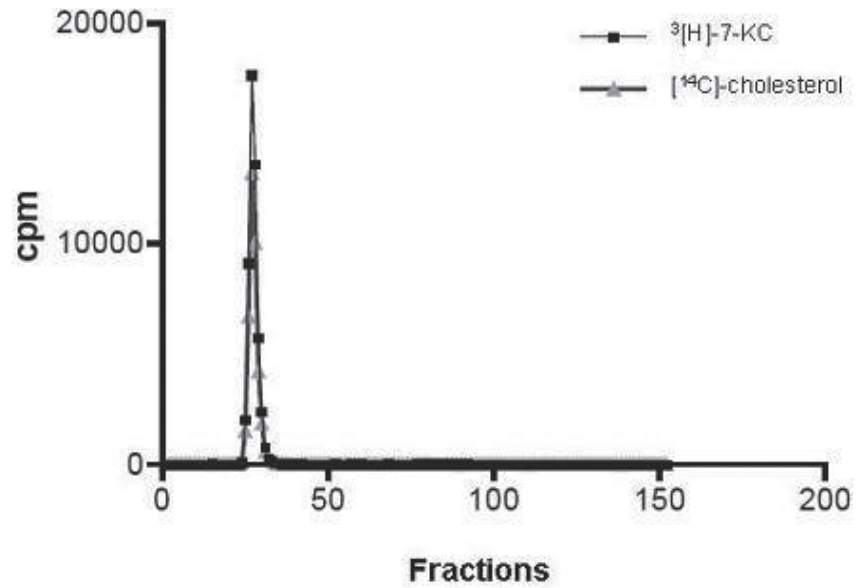

Figure 2: Column elution profile of $\left[{ }^{3} \mathrm{H}\right]$ 7-ketocholesterol and $\left[{ }^{14} \mathrm{C}\right]$-cholesterol contained in 7-KC-LDE.

Table 3

Effect of different concentrations of 7-KC incubated with LDE (7-KC/LDE) on the diameter of nanoparticles in layers 1, 3 and 4 obtained after ultracentrifugation.

\begin{tabular}{lccr}
\hline $7-\mathrm{KC}$ & Fraction 1 & Fraction 3 & Fraction 4 \\
\hline $2.0 \mathrm{mg}$ & $83.5 \pm 30.3 \mathrm{~nm}$ & $53.4 \pm 25.4 \mathrm{~nm}$ & $40.4 \pm 10.8 \mathrm{~nm}$ \\
$2.5 \mathrm{mg}$ & $99.7 \pm 36.8 \mathrm{~nm}$ & $50.4 \pm 6.1 \mathrm{~nm}$ & $39.8 \pm 17.4 \mathrm{~nm}$ \\
$5.0 \mathrm{mg}$ & $177.0 \pm 48.8 \mathrm{~nm}$ & $85.7 \pm 34.9 \mathrm{~nm}$ & $69.1 \pm 30.0 \mathrm{~nm}$ \\
$10.0 \mathrm{mg}$ & $201.8 \pm 59.5 \mathrm{~nm}$ & $106.9 \pm 45.8 \mathrm{~nm}$ & $113.0 \pm 51.5 \mathrm{~nm}$ \\
LDE & $54.7 \pm 26.8 \mathrm{~nm}$ & & \\
\hline
\end{tabular}

Values are mean $\pm S D$ of three different experiments

\section{Table 4}

Effect of different concentrations of 7-KC on the diameter of 7KC-LDE nanoparticles obtained by gel column chromatography

\begin{tabular}{lc}
\hline $7-\mathrm{KC}$ & Diameter \\
\hline $2.0 \mathrm{mg}$ & $62.4 \pm 28.7 \mathrm{~nm}$ \\
$2.5 \mathrm{mg}$ & $61.6 \pm 28.1 \mathrm{~nm}$ \\
$5.0 \mathrm{mg}$ & $63.4 \pm 29.5 \mathrm{~nm}$ \\
$10.0 \mathrm{mg}$ & $69.8 \pm 30.1 \mathrm{~nm}$ \\
LDE & $58.7 \pm 26.8 \mathrm{~nm}$ \\
\hline
\end{tabular}

Values are mean \pm SD of three different experiments
Figure 3 shows the plasma mean decay curves of 7-KCLDE. Progressive and similar decreases of both $\left[{ }^{14} \mathrm{C}\right]-$ cholesterol and $\left[1,2,6{ }^{3} \mathrm{H}\right]-7-$ ketocholesterol were observed with time. The decay curve is in the same range as those for LDE alone (data not shown).

Figure 4 presents the distribution of radioactivity derived from injected 7-KC-LDE. The liver was the main target for the particle, comprising around $50 \%$ of the injected radioactivity in the beginning of the experiment, and decreasing thereafter. Radioactivity was found to a much lesser extent in bowels and adrenals. In organs such as skin, heart, muscle, spleen, and brain, the radioactivity level was extremely low (data not shown).

Hematological parameters (hematocrit, hemoglobin, erythrocyte count, leukocyte differential count, and

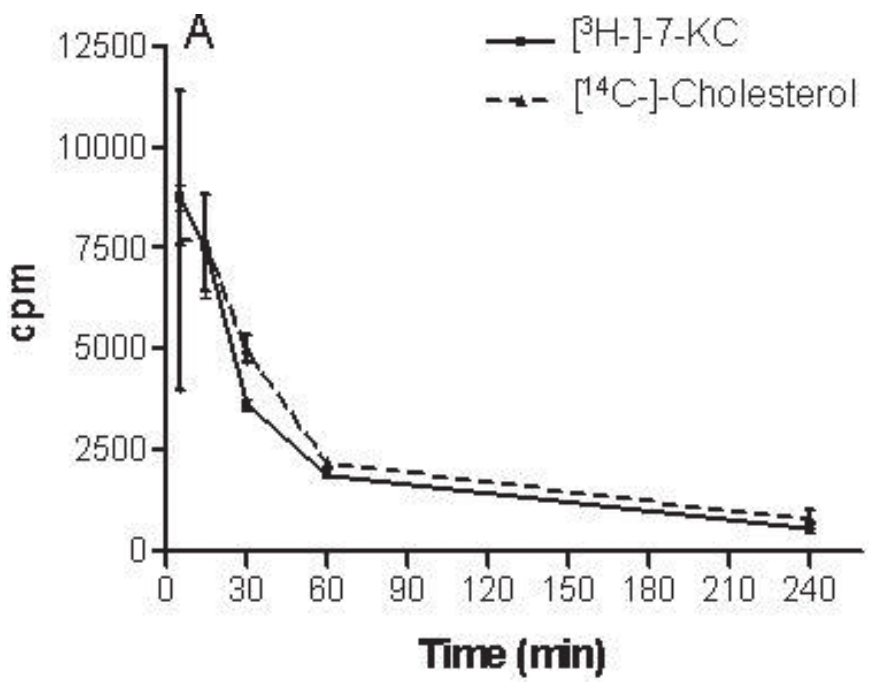

Figure 3: Decay curves of $\left[{ }^{3} \mathrm{H}\right]-7-\mathrm{KC}$ and $\left[{ }^{14} \mathrm{C}\right]$-free cholesterollabelled 7-KC-LDE injected intravenously as a single bolus into mice. Radioactivity was measured in a scintillation solution from plasma samples collected at the indicated times after injection.

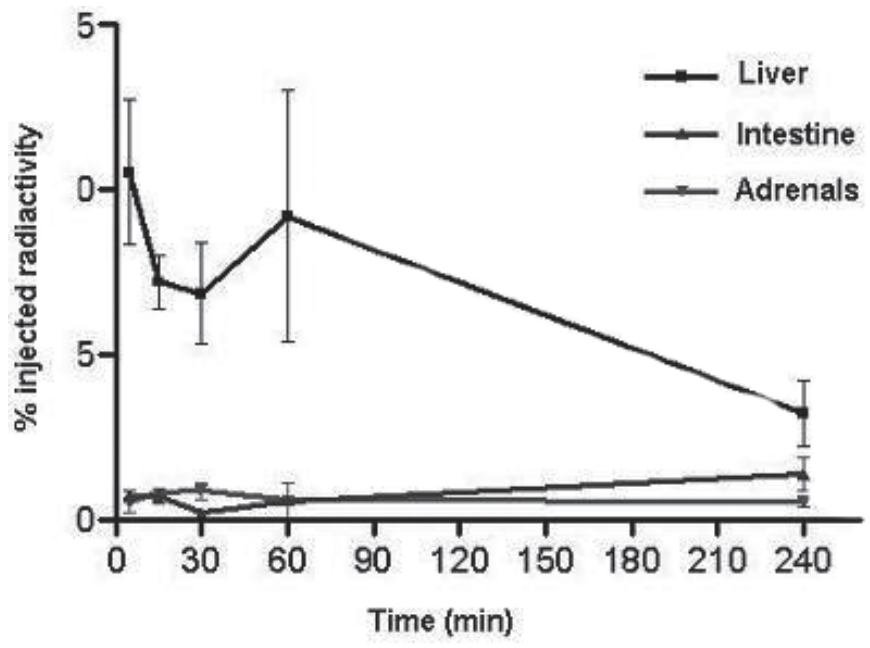

Figure 4: 7-KC-LDE radioactivity uptake by liver, bowels and adrenals from mice after intravenously injection as a single bolus. Radioactivity was measured in a scintillation solution after lipid extraction from samples collected at the indicated times after injection. 
eosinophil count) and liver enzymes (AST, ALT and GGT) in 7-KC-LDE injected animals were not different from controls (data not shown).

\section{DISCUSSION}

The aim of this study was to produce a 7-KC-containing nanoemulsion resembling LDL in order to provide an artificial nanoparticle suitable to study 7-KC metabolism in lipoproteins. For this purpose, two methods for incorporating $7-\mathrm{KC}$ were examined. When $7-\mathrm{KC}$ was added to the LDE particle already made (7-KC/LDE), it was successfully incorporated into the LDE, as shown by ultracentrifugation and TLC methods. It was also observed that different concentrations of $7-\mathrm{KC}$ led to different nanoemulsion characteristics. In fact, the results showed that varying the amounts of $7-\mathrm{KC}$ added to LDE, in the range of up to $10 \mathrm{mg}$, the lipid distribution in the nanoparticle was changed. Moreover, increasing 7-KC concentrations enhanced the particle size.

This was not observed by adding 7-KC to other lipid constituents of LDE at the beginning of its preparation (7$\mathrm{KC}-\mathrm{LDE}$ ). In this situation, 7-KC became an integral part of the particle, as shown by gel column chromatography. It is significant that the particle size did not differ from LDE when 7-KC was incorporated, at least in amounts of up to 10 $\mathrm{mg}$. Moreover, particles were stable at $4^{\circ} \mathrm{C}$ for more than one month, as also analyzed by the measurement of particle diameters with laser light scattering (data not shown).

To further explore the characteristics of 7-KC-LDE, in vivo experiments were performed. The plasma kinetics of this particle was quite similar to that of LDE. As expected, the liver, which has a great amount of LDL receptors, was the main target for the particle, comprising around $50 \%$ of the injected radioactivity in the beginning of the experiment, and decreasing thereafter. To evaluate toxicity, hematological parameters and liver enzymes were determined. No signs of toxicity were observed.

In conclusion, we were able to incorporate 7ketocholesterol in several amounts into LDE, a nanoparticle that was shown to resemble low-density lipoprotein in composition and behavior. The incorporation did not change the main lipid composition characteristics of the new nanoparticle or the particle size. The plasma kinetics and the targeted organs were also the same as described for LDE alone. Therefore, the 7-KC-LDE nanoparticle maintained the composition, size and some functional characteristics of LDE and could be used in experiments dealing with 7ketocholesterol metabolism in lipoproteins.

\section{ACKNOWLEDGEMENTS}

This research was supported in part by Conselho Nacional de Desenvolvimento Científico e Tecnológico (CNPq) and Instituto Nacional de Ciência e Tecnologia - Fluidos Complexos (INCT-FCx), Brazil.

\section{REFERENCES}

ALMEIDA KA, SCHREIBER R, AMANCIO RF, BYDLOWSKI SP, DEBESBRAVO A, ISSA JS, STRUNZ CM, MARANHÃO RC (2003) Metabolism of chylomicron-like emulsions in carriers of the S447X lipoprotein lipase polymorphism. Clin Chim Acta 335: 157-163.
BROWN MS, GOLDSTEIN JL (2009) The LDL receptor. Arterioscler Thromb Vasc Biol 29: 431-438.

BYDLOWSKI SP (1986) Mast cell: its mediators and effects on arterial wall metabolism. Gen Pharmacol 17: 625-631.

BYDLOWSKI SP, STIVALETTI VLG, DOUGLAS CR (1981) Effect of a low protein-high lipid diet on plasma lipid levels of rats. IRCS Med SciBiochem 9:834.

BYDLOWSKI SP, YUNKER RL, SUBBIAH MTR (1985) Delayed-effects of experimental maternal diabetes on plasma cholesterol level and vascular prostacyclin synthesis in the offspring. Proc Soc Exp Biol Med 179: 553-557

BYDLOWSKI SP, YUNKER RL, SUBBIAH MTR (1987) Ontogeny of 6-keto PGF1 \pm synthesis in rabbit aorta and the effect of premature weaning. Am J Physiol 252: H14-H21.

BYDLOWSKI SP, VINAGRE CG, BRAVO LM, DEBES AA, MARANHÃO RC (1995) Synthetic oligonucleotide does not bind to lipid emulsion resembling low-density lipoprotein. Ann N YAcad Sci 772: 252-254.

BYDLOWSKI SP, NOVAK EM, ISSA JS, FORTI N, GIANNINI SP, DIAMENT J (1996) DNA polymorphisms of apolipoprotein B and AICIII-AIV genes in a Brazilian population. A preliminary report. Braz J Med Biol Res 29: 1269-1274.

AMARAL VF, BYDLOWSKI SP, PERANOVICH TC, NAVARRO PA, SUBBIAH MT, FERRIANI RA. (2005) Lipid peroxidation in the peritoneal fluid of infertile women with peritoneal endometriosis Eur J Obstet Gynecol Reprod Biol 119: 72-75.

FAVERO GM, MARANHÃO RC, BYDLOWSKI SP (2008) Development of a synthetic 7-ketocholesterol-rich emulsion resembling chylomicrons. Lat Am J Pharm 27: 244-246.

GINSBURG GS, SMALL DM, ATKINSON D (1982) Microemulsions of phospholipids and cholesterol esters. Protein-free models of low density lipoprotein. J Biol Chem 257: 8216-8227.

GINSBURG GS, WALSH MT, SMALL DM, ATKINSON D (1984) Reassembled plasma low density lipoproteins. Phospholipidcholesterol ester-apoprotein B complexes. J Biol Chem 259: 6667-6673.

GREGORIO-KING CC, COLLIER FM, BOLTON KA, FERGUSON M, HOSKING JB, COLLIER GR, KIRKLAND MA (2002) Effect of oxysterols on hematopoietic progenitor cells. Exp Hematol 30: 670678.

HEVONOJA T, PENTIKAINEN MO, HYYVONEN MT, KOVANEN PT, ALA-KORPELA M (2000) Structure of low density lipoprotein (LDL) particles: basis for understanding molecular changes in modified LDL. Biochim Biophys Acta 1488:189-210.

HUNGRIA VTM, LATRILHA MC, RODRIGUES DG, BYDLOWSKI SP CHIATTONE CS, MARANHÃO RC (2004) Metabolism of an artificial emulsion resembling chylomicrons in patients with multiple myeloma. Cancer Chemother Pharmacol.53: 51-60.

JAVITT NB (2008) Oxysterols: novel biologic roles for the 21st century. Steroids 73: 149-157.

MARANHÃO RC, TERCYAK AM, REDGRAVE TG (1986) Effects of cholesterol content on the metabolism of protein-free emulsion models of lipoproteins. Biochim Biophys Acta 875: 247-255.

MARANHÃO RC, CESAR TB, PEDROSO-MARIANI SR, HIRATA MH MESQUITA CH (1993) Metabolic behavior in rats of a nonprotein microemulsion resembling low-density lipoprotein. Lipids 28: 691696.

MENDES S, GRAZIANI SR, VITORIO TS, PADOVEZE AF, HEGG R, BYDLOWSKI SP, MARANHÃO RC (2009) Uptake by breast carcinoma of a lipidic nanoemulsion after intralesional injection into the patients. A new strategy for neoadjuvant chemotherapy. Gynecol Oncol 112: 400-404.

OSADA K, HOSHINA S, NAKAMURA S, SUGANO M (2000) Cholesterol oxidation in meat products and its regulation by supplementation of sodium nitrite and apple polyphenol before processing. J Agric Food Chem 48: 3823-3829.

OWENS MD, BAILLIE G, HALBERT GW (2001) Physicochemical properties of microemulsion analogues of low density lipoprotein containing amphiphatic apoprotein B receptor sequences. Int J Pharm 228: 109-117

PRUNET C, LEMAIRE-EWING S, MENETRIER F, NEELI D, LIZARD G (2005) Activation of caspase-3-dependent and -independent pathways during 7-ketocholesterol and 7 $\beta$-hydroxycholesterolinduced cell death: a morphological and biochemical study. J Biochem Mol Toxicol 19: 311-326.

REDGRAVE TG, MARANHÃO RC (1985) Metabolism of protein-free lipid emulsion models of chylomicrons in rats. Biochim Biophys Acta 835: 104-112. 
RODRIGUES DG, MARIA DA, FERNANDES DC, VALDUGA CI, COUTO RD, IBANEZ OC, MARANHÃO RC (2005) Improvement of paclitaxel therapeutic index by derivatization and association to a cholesterolrich microemulsion: in vitro and in vivo studies. Cancer Chemother Pharmacol 55: 565-576.

RUSSEL DW (2000) Oxysterol biosynthetic enzymes. Biochim Biophys Acta 1529: 126-135.

SCHROEPFER Jr GJ (2000) Oxysterols: modulators of cholesterol metabolism and other processes. Physiol Rev 80: 361-554.
VEJUX A, KAHN E, DUMAS D, BESSÈDE G, MÉNÉTRIER F, ATHIAS A, RIEDINGER JM, FROUIN F, STOLTZ JF, OGIER-DENIS E, TODDPOKROPEK A, LIZARD G (2005) 7-ketocholesterol favors lipid accumulation and colocalizes with Nile Red positive cytoplasmic structures formed during 7-ketocholesterol-induced apoptosis: analysis by flow cytometry, FRET biphoton spectral imaging microscopy, and subcellular fractionation. Cytometry A 64: 87-100. 